\title{
O NASCIMENTO DO DISCURSO PATOLOGIZANTE DA OBESIDADE
}

THE BIRTH OF PATHOLOGIZING DISCOURSE OF OBESITY

EL NACIMIENTO DEL DISCURSO PATOLOGIZANTE DE LA OBESIDAD

Cezar Barbosa Santolin*, Luiz Carlos Rigo**

Palavras-chave

Obesidade.

História.

Patologia.
Resumo: Com o intuito de explorar a emergência do conceito de obesidade, o presente estudo histórico teve como referência teórico-metodológica a análise de discurso arqueogenealógica de Michel Foucault, concentrando-se nas inflexões estéticas, ético-morais, religiosas e biológicas nos primórdios da patologização do excesso de gordura corporal. De meados do século XVII ao XIX, os discursos médicos investiram na patologização da feiura dos corpulentos, da gula dos pecadores e do vício dos intemperantes. Desde a enunciação como doença da feiura até a medicalização do discurso, a patologização da condição caracteriza-se como um acontecimento relativamente recente no Ocidente, diferentemente do que alguns historiadores propõem.

\section{Keywords}

Obesity.

History.

Pathology.

Palabras clave

Obesidad.

Historia.

Patología.
Abstract: In order to explore the emergence of the concept of obesity, this historical study is theoretically and methodologically referenced on Michel Foucault's archaeo-genealogical discourse analysis, focusing on the aesthetic, ethical, moral, religious and biological inflections in the early pathologization of excess body fat. From the mid-17th to the 19th century, medical discourses invested in pathologizing ugliness of the corpulent, the gluttony of sinners and the vice of the intemperant. From enunciation of ugliness as disease to medicalization of discourse, pathologization of that condition is a relatively recent development in the West, as opposed to some historians' views.

Resumen: Con el fin de explorar la aparición del concepto de la obesidad, este estudio histórico tuvo referencia teórico-metodológica el análisis de discurso arqueológico y genealógico de Michel Foucault, concentrándose en las inflexiones estéticas, éticas, morales, religiosas y biológicas en los inicios de la patologización del exceso de grasa corporal. Desde mediados del siglo XVII y hasta el siglo XIX, los discursos médicos invirtieron en la patologización de la fealdad de los corpulentos, de la glotonería de los pecadores y de los vicios de los intemperados. Desde la enunciación de la fealdad como una enfermedad hasta la medicalización del discurso, la patologización de la condición se caracteriza como algo relativamente reciente en Occidente, a diferencia de lo que proponen algunos historiadores.
*Universidade Estadual do Oeste do Paraná (UNIOESTE). Marechal Cândido Rondon (PR), Brasil.

E-mail: cezarsantolin@ hotmail.com

** Universidade Federal de Pelotas (UFPEL). Pelotas, RS, Brasil.

E-mail: Icrigo@ terra.com.br

Recebido em: 02-04-2014 Aprovado em: 21-01-2015 (c) (i) () Licence 


\section{INTRODUÇÃO}

Imersos num presente lipofóbico, com limitada perspectiva sociocultural e histórica, muitos ocidentais contemporâneos teriam dificuldades de imaginar um mundo em que não existisse a noção de que há uma quantidade ideal de gordura ou massa corpórea. Mais custoso ainda seria imaginar a não existência da noção de tecido adiposo ou de massa corporal. Apesar disso, tais ideias nem sempre existiram e ainda hoje há culturas que não possuem tais conceitos (KULICK; MENELEY, 2005).

Embora alguns historiadores da obesidade, como Bray (2009), (2007) e Repetto (1998), especulem que o conceito de "excesso de gordura corporal" existia na Idade Média, na Antiguidade e até mesmo na Pré-história, os resultados de nossas investigações baseadas em fontes históricas indicam uma datação bem mais recente para 0 aparecimento desse conceito no Ocidente, principalmente para a enunciação de que essa condição seria uma doença.

Neste artigo, encontra-se o resultado parcial das pesquisas sobre a história da obesidade em que se investigou o período de emergência dos enunciados que afirmam que a condição "excesso de gordura corporal" seria uma doença. Durante esse período, denominado aqui de nascimento da obesidade - delimitado, de acordo com as fontes encontradas, entre meados do século XVII e meados do XIX -, os discursos que problematizam patologicamente o excesso de gordura corporal ainda não possuem a sustentação teórica da atualidade: estatística populacional, normalidade quantificada, índice de massa corporal (IMC), conceito de risco e de expectativa de vida. Assim, as justificativas para a patologização se equilibraram sobre princípios morais, éticos, estéticos e religiosos, provenientes de momentos históricos anteriores. Aparentemente, a aceitação geral de tais tipos de argumentos não pareceu problemática aos viventes da época. Em parte, porque os critérios de cientificidade da época eram outros, bastante diferentes dos atuais.

A absorção pela medicina dessas condenações e a inserção destas numa trama anatomofisiológica corresponde ao que Foucault (2001) denominou medicalização do discurso e que neste trabalho é chamado de discurso patologizante'. Além das características apresentadas pelo filósofo - sintomatologia, nosografia, classificação e taxionomia -, acrescentamos: 1) a enunciação, por parte de agentes específicos, segundo a qual os sujeitos portadores de determinadas características são doentes; 2) a proposição ou imposição de um tratamento - que é o momento de exercício efetivo do saber-poder, entendido como submissão, voluntária ou não, do doente ao terapeuta ou ao "complexo industrial terapêutico" (OLIVER, 2006). As práticas que se outorgam ou almejam o estatuto de terapêuticas necessitam de um discurso patologizante que as fundamente e legitime para o estabelecimento de uma relação de saber-poder deste tipo.

O presente estudo justifica-se principalmente pela relevância biopolítica² (PELBART, 2003, FOUCAULT, 2008, 2008b) que o tema da obesidade alcançou nos séculos XX e XXI, na perspectiva que apontam estudos como: Gomes, (2006); Rigo e Santolin (2012); Palma et al. (2012); Seixas e Birman (2012). Partimos do pressuposto que investigar a emergência deste conceito é uma estratégia de problematização das práticas discursivas e não discursivas que atualmente nos interpelam e nos governam.

1 Realizou-se esta modificação pois tais discursos não se restringem aos médicos, como pode ser inferido, equivocadamente, a partir da palavra "medicalização".

$2 \mathrm{Na}$ obra principal sobre o tema, Foucault $(2008 \mathrm{~b}, \mathrm{p}$.431) apresenta a seguinte definição para o termo biopolítica: "a maneira como se procurou, desde o século XVIII, racionalizar os problemas postos à prática governamental pelos fenômenos próprios de um conjunto de viventes constituídos em população: saúde, higiene, natalidade, longevidade, raças, ...". Apesar do filósofo não apresentar uma definição do 


\section{CONSIDERAÇÕES TEÓRICAS E METODOLÓGICAS}

A presente pesquisa se caracterizou como histórica, empregando na sua elaboração tanto fontes históricas primárias quanto secundárias. De acordo com Struna (2007, p.191), as fontes históricas secundárias são livros, artigos e outros meios nos quais outros pesquisadores contam histórias sobre o mesmo tema e que servem como ponto de partida para a pesquisa de fontes primárias, que seriam os "indícios reais" produzidos no passado.

No caso da presente pesquisa, após um levantamento bibliográfico e busca por palavras-chave na internet ${ }^{3}$ de materiais em língua portuguesa e inglesa, os autores encontraram um total de três artigos/capítulos de livros (REPETTO, 1998; HASLAM, 2007; BRAY, 2009) sobre a história da obesidade, que serviram como fontes históricas secundárias na composição de amostra bibliográfica para esta pesquisa e que, como tais, serviram de ponto de partida para a pesquisa das fontes primárias.

Devido às dificuldades de acesso às fontes primárias de séculos passados, apelou-se para materiais históricos digitalizados através do Gutenberg Project, da empresa Google, e disponibilizados, gratuitamente, através da base de dados Google Livros. O fato de tais fontes serem acessíveis a todos pesquisadores permite que a pesquisa seja replicável em sua metodologia - uma das características desejáveis para a pesquisa científica, de acordo com Thomas, Nelson e Silverman (2007).

A busca na ferramenta foi efetuada, primeiramente, em torno da palavra-chave "obesidade", em português, seguida de suas variações contemporâneas da língua inglesa obesity e francesa obésité. Utilizaram-se ferramentas de busca disponibilizadas no site para estabelecer períodos cronológicos específicos de modo a verificar o número de ocorrências por século. Como o propósito da pesquisa foi verificar a construção conceitual do discurso patologizante, a escolha das fontes privilegiou obras de caráter médico-científico, utilizando os títulos do resultado da busca para selecionar, em vista de um exame posterior mais detalhado em seus conteúdos, aquelas que possuíssem termos relacionados à medicina, como "tratado", "medicina" (medecine, medicine), "patologia" e "nosologia" (nosologie).

Com o início da leitura dos textos das fontes primárias, à medida que a pesquisa avançava, constatou-se a existência de uma maior variedade de termos para se referir a condições díspares que poderiam ser confundidas com o conceito de obesidade contemporâneo, tecnicamente definido pela Organização Mundial da Saúde (OMS). Deste modo, foi necessário ampliar o rol de palavras-chave pesquisadas, incluindo "corpulência", corpulence, embonpoint, fatness e "polisarquia" - cujos significados serão fornecidos posteriormente no texto.

A respeito da seleção das fontes, ressalta-se, entretanto, que algumas obras e autores foram buscados a partir da referência a estes nas fontes secundárias ou primárias. A recorrência de citações de certas obras e autores nas fontes primárias pode ser interpretada como indício de relevância histórica, pois são portadores de um saber-poder supostamente diferenciados em relação a leigos.

Um último critério de seleção utilizado foi o estabelecimento da relevância histórica a partir de fontes historiográficas que poderiam ser classificadas como terciárias, por não tratarem especificamente do tópico da história da obesidade, como no caso de Magner (2005) - historiador da

3 As palavras-chave pesquisadas foram "história" e "obesidade", tanto em português quanto em inglês. 
medicina. Além desta fonte terciária, utilizou-se para a seleção das fontes o critério de relevância histórica bem estabelecida, como no caso das enciclopédias iluministas, cujo impacto e relevância histórica na formação de opinião e difusão do conhecimento no final do Século XVIII são incontestes.

Deste modo, cruzando as fontes secundárias, as fontes primárias médico-científicas, as fontes primárias e secundárias relacionadas e as fontes terciárias, buscou-se produzir uma rede que permitisse a elaboração de uma narrativa histórica. Ressalta-se, entretanto, que a narrativa construída e apresentada, assim como todas as histórias, está e permanecerá aberta no sentido de que novas fontes históricas e/ou interpretações das fontes possam reconfigurar, modificar, complementar, reduzir, deslegitimar ou questionar essa narrativa.

Apesar de termos nos apoiado em uma série de fontes históricas, também foi feita uma descrição interna de cada uma das fontes utilizadas. A este procedimento, Foucault (2008a) dá o nome de descrição interna do monumento. Ressalta-se, entretanto, que esta análise interna, como que finalizada em si mesmo, é relativa, já que é impossivel qualquer análise discursiva de um texto completamente finalizada em si.

A aplicação desta metodologia permitiu o estabelecimento de aproximações e distanciamentos entre os sistemas de pensamento presentes em fontes distintas, a partir do conteúdo dos conceitos empregados e do núcleo argumentativo, para sustentar uma problematização patologizante da condição apresentada.

Metodologicamente, além desses procedimentos com as fontes, que Foucault (2008a) denomina de arqueologia do saber, uma maneira de tratar as fontes históricas - inclusive as bibliográficas - como monumentos ou peças arqueológicas que são utilizadas para a construção de uma narrativa sobre o passado, efetuou-se também uma análise dos discursos, na perspectiva utilizada por Michel Foucault (2008a; 1996), das práticas discursivas que atuaram no processo de patologização da obesidade.

\section{AS LUZES ENCICLOPÉDICAS}

Tendo em vista a relevância histórica do enciclopedismo no século XVIII, buscou-se reconstruir o pensamento que é tomado como representativo do período que vai de meados do século XVII a meados do XVIII4, a partir dos textos que compõem dois verbetes - obésité/ obesity e corpulence/fatness ${ }^{5}$ (DIDEROT, 1777, p.537; CHOMEL, 1743, p.214; CHAMBERS, 2012, 2012a) - que estão presentes nas enciclopédias francesa e britânica respectivamente, além de autores referenciados nestes e em outros compêndios médicos.

Além dos verbetes, três obras citadas nas enciclopédias foram encontradas: Ettmuller ${ }^{6}$ (1699), Allen7 (1728) e Boerhaave ${ }^{8}$ (1746). As concepções acerca das temáticas presentes em

\footnotetext{
4 A representatividade aqui alegada foi estabelecida a partir do restante da pesquisa histórica empreendida, em que foi identificada a duração de cerca de um século de um certo padrão argumentativo e conceitual para a problematização do corpo considerado demasiadamente grande e da fome considerada exagerada.

5 Tais verbetes foram escolhidos por não serem encontrados outros que direta ou indiretamente estivessem relacionados ao tema, o que sugere que estes seriam os únicos ou os principais substantivos utilizados para descrever tais condições nas línguas inglesa e francesa.

6 Michael Ettmuller (1644-1683) foi um médico alemão que teria viajado pela França, Itália e Inglaterra - o que explicaria a inclusão de seus conceitos na Enciclopédia. Ettmuller (1699, p.607) inclui um pequeno capítulo sobre "a grande corpulência" a respeito da "nutrição das partes", referindo-se à distribuição do sangue, que hoje denomina-se grande circulação. Esse processo poderia ser "atrapalhado" de três formas, dentre as quais a obésité.

70 texto só cita J. Allen, que foi doutor em medicina inglesa. Não foram encontradas mais informações a respeito. 
tais textos, sobretudo na francesa, constituem quase integralmente o conteúdo dos verbetes. Além de uma mesma formação discursiva, pode-se afirmar que esses médicos tiveram impacto significativo durante o período em questão e, consequentemente, no nascimento do discurso patologizante da obesidade.

Primeiramente, é necessário esclarecer o que as palavras corpulence e obésité, que eram usadas como sinônimas, significavam ou em que sentido elas eram empregadas nesses discursos. Tanto Allen (1728) quanto Chomel (1743) apresentam a mesma definição que Ettmuller (1699), a qual, simplificadamente seria "embonpoint excessivo". Cabe, portanto, explorar o significado desta construção lexical através de justaposição, em língua francesa, da expressão "em bom ponto" (ETYMONLINE, 2014), que:

[...] ocorre quando todas as partes são abundantemente regadas pelo suco nutritivo, que os corpos estão macios e rechonchudos [roliços], em uma palavra cheia de suco; denomina-se os corpos neste estado corpos quadrados, o que queremos dizer é que as partes são nutridas em todas as suas dimensões, que dão ao corpo sua força, a beleza e a consistência exigidas. (ETTMULLER, 1699, p.608-609).

$\mathrm{O}$ adjetivo assume um papel valorativo positivo como contraponto à negatividade do corpulence ou obésité - que nesta definição não se relacionam ao IMC, massa ou gordura corporais. Estar "em bom ponto" é, sobretudo, uma questão estética ${ }^{9}$ - o que realmente importa é o fato da aparência corporal apresentar uma forma (quadrada) e ter desenvolvido suas dimensões proporcionalmente. Por conta disso, o "diagnóstico", como sugere este médico, seria fácil, já que seria visual.

As qualidades para estar "em bom ponto" - força, beleza e consistência - são "exigidas", na passagem supracitada, por um sujeito oculto ou indeterminado, mas que, possivelmente, fala em nome do gênero masculino. Ainda em meados do século XIX, ser macia, rechonchuda ou embonpoint eram consideradas qualidades femininas - demandas que eram direcionadas quase que exclusivamente às mulheres e que só podiam ser cumpridas por uma pequena parcela socioeconomicamente privilegiada delas (GRAHAM, 1827; THE SPECTATOR, 1865).

O corpo embonpoint é suculento, resguardando uma analogia com a gastronomia da carne "no ponto" - gostosa. A mulher que emagrece demais fica seca, perdendo seu "delicioso embonpoinf' (BRILLAT-SAVARIN, 1854, p.269), e aquelas que acumulam suco em demasia se tornam obèse.

Assim, a "obésité ou embonpoint excessivo, que denominamos também de corpulence, ocorre quando todo o corpo, tanto o abdome quanto os outros membros aumentam de volume" (CHOMEL, 1743, p. 214) ou "é quando o corpo está aumentado em sua circunferência, tanto em relação ao estômago quanto de outros membros" (ETTMULLER, 1699, p.609).

Tem-se, portanto, a problematização de uma condição a partir de parâmetros estéticos: o volume, a circunferência, a forma e a beleza. Essa faceta também pode ser constatada em outras definições que são apresentadas. Ettmuller (1699, p.608), por exemplo, afirma que "obésité é quando a gordura enche e encrosta nas membranas das partes, especialmente naquelas embaixo da pele". Ele explica que, em pessoas com grande corpulência, além dos músculos, pode-se observar gordura grudada a órgãos e a outras partes. Neste caso, a substância inde-

90 termo "estética" é utilizado neste artigo para referir-se a juízos de valor referentes ao que é belo e a certos padrões de beleza corporal e não para se referir aos gostos, às sensações e sensorialidade, como utilizado em alguns ramos da Filosofia. 
sejada aparece como objeto discursivo relacionado à perda das características estéticas do embonpoint, pois não se trata de qualquer gordura encrostada, mas daquela que fica embaixo da pele, que deforma, desfigura, enfeia o formato do corpo, tirando seu aspecto quadrado considerado belo.

Os verbetes apresentam, ainda, outras facetas que demonstram que o conceito permitia leituras que estavam além do volume, da circunferência e da gordura subcutânea encrostada, considerados excessivos, como, por exemplo, "a obésité ou corpulence não consiste no aumento dos sólidos, mas em sua dilatação extraordinária, causada pela abundância de humores que contém" (BOERHAAVE apud DIDEROT, 1777, p.537). 0 excesso de humores - pletora ${ }^{10}$ - causaria uma dilatação extraordinária dos componentes sólidos do corpo, o que seria, aparentemente, a definição de obesidade ou corpulência. Dizemos aparentemente por se referir a um aspecto etiológico ao invés da essência da condição patologizada, que permaneceria sendo a questão do volume, da circunferência, do formato e da beleza corporal.

Nos verbetes enciclopédicos analisados não se comenta em relação a que parâmetro o volume, a circunferência, a gordura encrostada, os sólidos, o embonpoint ou a massa corporal deveriam ser considerados excessivos. Não se emprega o termo média ou normal, nem se sugerem medidas. Qual seria, então, o problema com aquelas características? Apesar da problematização da corpulência, advinda das condenações morais e estéticas, nota-se uma dificuldade em sustentar a normatividade e inserir tais condições, legitimamente, entre as doenças. Boerhaave (1746), por exemplo, insere-a não como uma doença, mas como uma causa para um sintoma - apetite exacerbado - ou seja, o inverso do que se acredita contemporaneamente que seria a corpulência que causaria um distúrbio no apetite e não o inverso. Neste caso, a condição entra de uma maneira duplamente secundária, por ser causa de um sintoma e por ser apontada como menos importante do que a diminuição do apetite.

Já Ettmuller (1699, p.609) justifica a problematização das circunferências e volumes excessivos pelo fato de que "as ações são consideravelmente impedidas e fere a todos aqueles que observam o movimento" - motivo também apresentado na enciclopédie (CHOMEL, 1743; DIDEROT, 1777). Alegações estéticas: as circunferências do estômago, dos membros e do corpo são relacionadas a um impedimento dos movimentos, que incomodaria não seu executor, mas os outros - aqueles que observam. Trata-se de uma questão de formato corpóreo e de beleza do movimento - enfim, uma protopatologização da feiura.

Para fugir dessa dificuldade de justificar uma problematização patológica de atributos estéticos e/ou morais, apelar-se-á para as explicações causais - a etiologia, a trama de causas e os efeitos anatomofisiológicos, que ainda se situam, principalmente, dentro do humoralismo, mas já com alguma influência mecanicista e quimicista (MAGNER, 2005). A medicina ainda não era quantitativa e as medidas que aparecem são valores absolutos de massa corporal recordes, como uma curiosidade (ETTMULLER, 1699; CHOMEL, 1743; DIDEROT, 1777; ALLEN, 1728).

Apesar disso, a condição não deixou de ser inserida num encadeamento discursivo quase fantástico de causalidades com desfecho amedrontador - a morte súbita. Ainda que 0 conceito de morte súbita não tenha o mesmo significado que na contemporaneidade, o risco de

$10 \mathrm{Na}$ concepção humoralista, o corpo humano é como uma espécie de recipiente em que há quatro humores fluidos: o sangue, a fleuma, a bílis negra e a bílis amarela. Cada humor estaria presente em cada pessoa numa certa proporção, e a manutenção do equilíbrio entre estes humores garantiria a saúde, o que justificava a prescrição médica de sangria (extração do sangue), diuréticos, expurgos e vômitos, já que se destinavam a extrair o excesso de algum desses humores, reestabelecendo, assim, a proporção certa que garantia a saúde. Dessa forma, a pletora era descrita como uma condição em que havia excesso de humores - sem especificar exatamente qual dos quatro humores estariam em excesso (MAGNER, 2005). 
morte e o consequente poder de amedrontamento estava presente. Os especialistas também não deixaram de incluir tratamentos baseados, sobretudo, em aspectos alimentares que se justificavam a partir das causalidades humorais.

Além disso, são recomendadas atividades para estimular a transpiração, por isso deve-se não só cavalgar, caçar e correr, mas, também, andar "em carruagens que balançam e sacodem" (CHOMEL, 1743, p.214). Recomenda-se, por fim, evitar uma vida indolente, despreocupada, muito sono, as paixões, as preocupações e as tristezas. Pontua-se, neste momento, que o tratamento assume um aspecto duplo: para o corpo e para a alma; repletos de ascetismo, como se não fosse um tratamento, mas uma punição por seus "vícios" (FOUCAULT, 1998a). Pressupõe-se, portanto, uma causa advinda de algum comportamento excessivo em relação àquilo que seria considerado ideal e adequado. Esse excesso seria causado por um desvio moral ou de caráter, o que indica a emergência de uma noção de culpabilização do sujeito, bem especifica dessa época. Assim, apregoava-se transformar-se, atingir uma condição que seria mais satisfatória (CANGUILHEM, 1995).

\section{A PATOLOGIZAÇÃO DA FEIURA}

Numa pesquisa histórica, encontram-se, eventualmente, discursos impressionantes que dificilmente seriam proferidos no presente, e esse é precisamente um dos motivos que fazem com que esse tipo de abordagem seja imprescindível para a compreensão de um fenômeno sociocultural contemporâneo. Na obra de Sauvages ${ }^{11}$ (1772) é possível encontrar alguns enunciados dessa ordem.

Apesar desta obra não ter sido citada na enciclopédie, o texto compartilha quase toda a nosografia com aquela presente nos verbetes. Por que, então, não acrescentar este discurso à formação discursiva anterior? 0 que neste discurso impressiona e o diferencia daqueles? 0 espanto e a diferença advêm, principalmente, do aspecto explícito com que se pode constatar a apropriação, pela medicina, daquilo que é considerado feio e transformado em doença. Desse modo, declara-se, explicitamente, que o objeto que está sendo patologizado é a feiura.

Assim como o sistema botânico, a nosografia de Sauvages (1772) divide as doenças em classes, ordens e subclasses ou espécies. A corpulência ou polisarquia ${ }^{12}$ - termos utilizados como sinônimos - é incluída na décima classe, denominada doenças caquéticas ou caquexias, termo que significa feiura ${ }^{13}$.

O principal sintoma das doenças caquéticas "é uma deformidade, ou uma alteração considerável da forma natural" (SAUVAGES, 1772, p.31), sendo que:

[...] a forma ou a beleza consiste numa combinação de qualidades sensíveis, tais como a aparência, o volume, o nome, a proporção das partes, nos cabelos, na

\footnotetext{
11 François Boussier de Sauvages de Lacroix (1706-1767) foi um médico e botânico francês, sua nosografia baseava-se no sistema de Thomas Sydenham (1624-1689).

12 Etimologicamente, o termo polisarquia deriva da língua grega, sendo composta a partir da justaposição do prefixo poli-, que significa muitos, e do substantivo sarcos, que se referia aos músculos no sentido de "carne" (ETYMONLINE, 2014). Na Educação Física, palavras derivadas deste último termo podem ser vistas no estudo da fisiologia do músculo esquelético, como nos substantivos sarcômero, sarcoplasma e sarcolema. Teoricamente, a condição descrita pelo substantivo polisarquia seria "muitos músculos ou muitas carnes", entretanto, o termo foi utilizado por Sauvages (1772) com um significado que não levava em consideração a composição corporal, havendo somente uma assinalação de que o indivíduo portador desta condição possuía um corpo grande, volumoso, "carnudo" - independentemente se composto por gordura ou músculos. Mesmo sentido com que a palavra corpulência/corpulence foi empregada e ligeiramente diferente do conceito de obesidade, que é definida como "gordura corporal excessiva".

130 significado apresentado é baseado na definição do próprio autor, que será apresentada adiante. Atualmente, o termo significa "Estado de desnutrição profunda, produzido por diversas causas; enfraquecimento geral" (FERREIRA, 1984, p. 346).
} 
cor, na consistência, etc. como observamos nas pessoas que passam por belas; decorre daí que a ausência de uma dessas qualidades constitui a feiura, que, no entanto, não é mórbida, a menos que seja constante e notável, e acompanhada de outros sintomas, como é bastante comum. (SAUVAGES, 1772, p.31-33)

É neste sentido que a corpulência foi incluída entre as doenças caquéticas - uma patologia da feiura. A condição é:

[...] um excesso de embonpoint que desfigura os corpos [...] esta doença difere do tamanho gigantesco, mas bem proporcionado, que não diminui a beleza e cujas forças são proporcionais ao volume dos corpos. Esta doença difere do edema e do inchaço, em que o tecido não é preenchido com líquido seroso, nem flatos, mas de gordura, de modo que o tom da cor não seja alterado pela exposição. (SAUVAGES, 1772, p.106-107)

Por isso, não é o próprio sujeito que se considera doente e vê sua existência dificultada de algum modo, como na definição de saúde que aponta Canguilhem (1995), mas são os outros que 0 classificam como doente. Logo, se a fealdade ${ }^{14}$ pode ser, em algum grau - ainda que restritamente -, patologizada, entende-se que este processo só pode ocorrer através da comparação a um padrão socialmente estabelecido de beleza - histórico e culturalmente situado.

Para vincular a estética à anatomofisiologia, o corpo é comparado a uma máquina, de modo que, quando os órgãos falham, apresentando uma fisiologia "viciosa" e não correspondendo ao que se propõem, ocasionam uma deformidade, ou seja, uma caquexia. Com esse argumento a feiura pode ser legitimamente patologizada e inserida numa relação de saber-poder terapeuta/doente; desse modo, ser feio entra numa relação de significância como signo ou sintoma de que o corpo-máquina não está funcionando perfeitamente e, por isso, o médico deve exercer seu poder de intervenção para corrigir sua mecânica sob uma alegação terapêutica, visando restaurar a forma natural.

O olhar médico percorre do interior ao exterior do corpo, da menor molécula à forma corpórea, julgando aquilo que é ou não natural. Outorga-se um conhecimento da essência da natureza, da vida, do biológico - seus fins e seus meios - e o poder de determinar se a aparência ou a forma corporal é ou não natural - o que, curiosamente, equivaleria à beleza. Percebe-se, enfim, de que maneira a estética pode ser vinculada às "funções" biológicas e inseridas num discurso patologizante que a torna passível de medicalização. Ressalta-se, também, que o "natural" assume antes do "normal" o posto de ideal no discurso e que os médicos se colocam numa posição privilegiada de portadores de um saber que lhes permite conhecer a naturalidade de tudo e que, portanto, devem possuir o direito legítimo de definir e julgar o que é ou não natural e quem deve ser submetido à intervenção de seu poder (FOUCAULT, 1998).

A repugnância e a intolerância que se sente perante a fealdade podem ser transmutadas em algo moralmente aceitável, como a honrosa tarefa terapêutica de curar. Ao invés da estigmatização de um "gordo feio", tem-se a compassiva preocupação com a saúde de um doente. De uma relação coercitiva passa-se para o direito ao tratamento ${ }^{15}$.

A sintomatologia só pode ser construída depois desse "diagnóstico" da "deformidade" corporal, da caquexia ou da feiura. Assim, a polisarquia "diminui a agilidade [...] os músculos

14 "Qualidade de feio" (FERREIRA, 1984, p. 764) 
não se tornam fortes, o corpo se torna lento e preguiçoso, e é impossível fazer algo sem que a respiração sofra" (SAUVAGES, 1772, p.107).

Da mesma forma, a percepção de perigos só pode ser construída após o julgamento estético que determinará quem integrará o grupo de sujeitos que serão denominados corpulentos. Uma identidade constituída a partir de parâmetros estéticos é a condição de possibilidade para que o médico possa enunciar que "as pessoas corpulentas vivem, como é esperado, menos tempo que as outras, e são infinitamente mais sujeitas à apoplexia ${ }^{16}$ e à ortopneia"17 (SAUVAGES, 1772, p.107).

A etiologia deixa transparecer, também, alguns julgamentos morais, assim como os enciclopedistas: "uma dieta copiosa e suculenta, um hábito lasso, a passagem de um país frio para um país quente, a recuperação de uma synoque ${ }^{18}$ maligna, a alegria, a abundância, a ociosidade" (SAUVAGES, 1772, p.107-108). Não somente a alegria engorda, mas a tristeza, as preocupações, as emoções e paixões, que extenuam o corpo dócil (FOUCAULT, 2002).

O princípio causal se localizaria no estômago e mantém uma relação de analogia com a culinária e com o tratamento. A cura exige, ainda, "que não se durma demasiado, que se faça exercício, que se tenha o espírito em movimento, [...] que coma menos e que use alimentos menos nutritivos; que aumente as excreções, acima de tudo, a transpiração pelo exercício, a caça, a corrida, o uso legítimo das mulheres" (SAUVAGES, 1772, p.108-109). Faz-se necessário um corpo infinitamente útil que deve estar sempre ativo (FOUCAULT, 2002).

Tem-se, por fim, em tal fonte histórica, a primeira enunciação de que a corpulência e a gordura corpórea consideradas excessivas sejam doenças (CHAMBERS, 1851). A enunciação explicita, de forma muito crua, que tais condições estariam sendo assim consideradas por uma questão de beleza. Somente depois de instaurar esse parâmetro estético - a caquexia ou feiura - é que Sauvages (1772) irá construir uma nosografia, buscando associar sintomas a tais condições.

Considera-se esta fonte tão importante para a história da obesidade a ponto de ser incontornável aos historiadores o fato de que o primeiro enunciado de patologização foi motivado por um julgamento estético e não por evidências científicas, epidemiológicas, laboratoriais, empíricas. Sabe-se que tanto aquele quanto estas podem se constituir como dispositivos equivalentes de legitimidade, operando discursos diversos de normalidade. Entretanto, as histórias da obesidade encontradas, como Repetto (1998), Haslam (2007) e Bray (2009), ressaltam as segundas, apelando para a maior legitimidade científica perante o julgamento contemporâneo. Dessa forma, ressalta-se aqui o dispositivo de legitimação estético como contraponto a tais historiografias, com o intuito de explicitar o que estava implícito - seja por esquecimento, omissão ou ocultamento deliberado. Assim, demonstra-se que nós, modernos, ousamos patologizar - ou seja, "desvalorar uma existência" (CANGUILHEM, 1995) - através de um processo que se iniciou, predominantemente, com uma desvaloração estética, culturalmente construída e historicamente situada.

16 A condição denominada apoplexia se referia ao que atualmente se denomina acidente vascular encefálico ou, popularmente, derrame. 17 Atualmente, ortopneia é descrita como uma condição em que a pessoa tem dificuldade respiratória (FERREIRA, 1984). No texto de Sauvages (1772) não foi encontrada uma definição desta condição, mas a passagem permite supor que, possivelmente, foi empregado 0 significado atual.

18 Não foram encontradas maiores informações sobre esta condição nem no texto de Sauvages (1772) nem em outros materiais, inclusive em dicionários da época ou em dicionários etimológicos contemporâneos. Apesar disso, é possível supor, a partir da passagem em que foi empregado, que o termo se referia a uma condição patológica. 


\section{DESINFECÇÃO DISCURSIVA}

As duas enunciações que serão abordadas nesta seção - a de Flemyng ${ }^{19}$ (1760) e a de Brown $^{20}$ (1788) - diferem das anteriores na medida em que nelas não se encontram adjetivos com conotações estéticas, como, por exemplo, embonpoint. A medicalização do discurso já atua, ainda que sutilmente, para realizar aquilo que pode ser denominado uma assepsia, ou seja, uma limpeza dos termos utilizados para transformar discursos estéticos e morais numa questão biológica.

Mesmo que os médicos já estivessem trabalhando na construção de um discurso patologizante desde o final do século XVIII é somente a partir da segunda metade do século XIX, com trabalhos como o de Banting (1864), que a patologização da gordura irá se tornar um discurso mais popular.

Além da desestetização e da desmoralização, os discursos desta formação discursiva se caracterizam por já não falarem de humores e sucos corporais, ou seja, de resquícios de humoralismo, tão presentes nos discursos anteriores. Mesmo a confusão conceitual é desfeita, o que enfatiza que a enfermidade descrita é "um aumento da quantidade de gordura e não de sangue ou qualquer outra substância que seja" e isto seria "tão claro e evidente que nós podemos nos poupar o trabalho de prová-lo. Açougues evidenciam suficientemente esta verdade e o senso comum da humanidade consente" (FLEMYNG, 1760, p.1-2). Também Brown (1788) enuncia que a obesidade é um acúmulo de gordura.

Apesar dessas diferenças nos discursos da época, muitas semelhanças podem ser encontradas, como, por exemplo, a inexistência de discursos que se apropriam de estatística populacional, do IMC, ou dos atuais conceitos de normalidade, risco e expectativa de vida. Como foi, então, justificada tal problematização? Para enunciar que a condição é uma patologia, Brown $(1788$, p.1) remete à sua própria definição de doença, que traz o termo "má saúde" e que "consiste num exercício difícil e perturbado de todas ou de algumas funções"; enquanto Flemyng (1760, p.1) afirma que "a corpulência, quando num grau extraordinário, pode ser reconhecida como uma doença, uma vez que, em alguma medida, obstrui o exercício livre das funções animais". Além destas alegações, Flemyng (1760) e Brown (1788) afirmam que a corpulência ou a gordura corporal "extraordinárias" teriam "uma tendência para encurtar a vida" (FLEMYNG, 1760, p.1) ou deixariam a pessoa afetada "predisposta a outras doenças" (BROWN, 1788, p.117), assim como as demais formações discursivas analisadas. Sem quaisquer sustentações científicas similares às atuais, que seriam contemporaneamente aceitáveis, tais enunciados se aproximam dos discursos cristãos, como pode ser percebido num dos perigos sugeridos: "pavimentação do caminho para intemperanças perigosas" (FLEMYNG, 1760, p.1). Além da noção de temperança, há um paralelo do argumento cristão, em que o pecado da gula poderia levar a outros pecados mais graves, como a fornicação, sendo necessário, por conta disso, evitá-lo (AQUINO, 1984; CORNARO, 2011).

Dando sequência às explicações fisiológicas, Flemyng (1760) acrescenta que a gordura seria secretada pelo sangue, mas que não permaneceria misturada a este. 0 médico é um

19 Malcolm Flemyng (1700-1764) foi um fisiologista escocês. Embora o material de Flemyng (1760) tenha sido lido em 1757 perante à Sociedade Real britânica, desconhece-se a importância que seu discurso teve no meio médico da época, além disso, sua teoria parece ter sido fortemente influenciada pela de seu tutor - Herman Boerhaave.

20 John Brown (1735-1788) foi um médico escocês e teve como tutor William Cullen. A teoria de Brown (1788) sobre a obesidade parece que teve pouquíssima ou nenhuma repercussão, tendo em vista que não foram encontradas outras obras que utilizassem o mesmo sistema de pensamento e conceitos. 
dos poucos a sugerir algumas funções positivas para esta substância tão infame, como a lubrificação, a prevenção da fragilidade dos ossos, o preenchimento de fendas e interstícios, a contribuição na matéria da bile e a aquisição de uma lustrosa beleza para a pele. A mecânica assume a função de grade de inteligibilidade para as funções que a gordura exerceria no corpo.

A etiologia e os tratamentos sugeridos seguem a tendência das formações discursivas anteriores, concentrando-se sobre o excesso alimentar e indicando restrições, além de caminhadas vigorosas, jogo de tênis, trabalhos físicos, casa de banho, etc. para aumentar a sudorese, por esta conter óleo. Todas as explicações e sugestões são permeadas por uma condenação ética, moral e religiosa de fundo, apesar de não tão explícita como em Cornaro (2011).

Já a etiologia apresentada por Brown (1788) difere consideravelmente de qualquer outra apresentada. A origem de qualquer doença violenta começaria com um estímulo solitário, que recairia sobre uma parte e se alastraria para o restante do corpo, a menos que outro estímulo aplicado a outras partes interrompesse essa operação e impedisse que todo o corpo fosse afetado.

Assim, a obesidade integraria a classe de doenças denominada "apirexia estênica"¹, que significa que não há febre (apirexia), mas um estado de atividade exacerbada no estômago (estênica). Os poderes digestivos, que originam a força e o vigor, funcionariam mais perfeitamente nas pessoas gordas, tornando tais poderes excessivos, prejudiciais, levando ao desperdício da excitabilidade num alto grau de distúrbio e a exaustão do corpo. Em consequência disso, as paixões ou os desejos sexuais seriam menos estimulantes para essas pessoas, além de ser:

[...] observável que pessoas gordas são adversas a pensar por ser um grande estímulo. Eles têm aversão ao movimento corporal, no qual todas as funções e, principalmente, os vasos sanguíneos são muito excitados e promove, proporcionalmente, a perspiração; e eles tem uma razão justa para isto já que todo movimento é mais fatigante para eles que para os outros. (BROWN, 1788, p.123)

A respeito das causas, esse médico afirma que o surgimento seria "em consequência de um excesso de saúde, vida rica, especialmente nos artigos alimentares e de um modo de vida fácil e sedentário" (BROWN, 1788, p.117).

Constata-se, por fim, que tanto em Flemyng (1760) quanto em Brown (1788) o núcleo conceitual "gordura corporal excessiva" já estava claramente delineado nas definições apresentadas. Há, ainda, um esforço para desinfectar o discurso patologizante de suas características originais, principalmente estéticas e morais. Trata-se de transformar um discurso estético e/ou moral num discurso biopatologizante.

Apesar do esforço, buscou-se ressaltar de que forma esse objeto discursivo era tratado, principalmente através de pressupostos valorativos estéticos, morais e religiosos. Pode-se almejar a "desinfecção" dos discursos normativos, mas esses resistem em ser plenamente esterilizados, permanecendo com "micro-organismos" estéticos, morais, religiosos e políticos,

21 Brown (1788) descreve uma escala das doenças estênicas posicionando as que causam febre e inflamação acima daquilo que ele denominou saúde perfeita, enquanto a mania, o pervigilium e a obesidade se posicionavam abaixo de tal escala, como doenças apiréxicas, ou seja, que não causam febre e inflamação. Na apirexia estênica os poderes estimulantes seriam mantidos num grau de força que desperdiçaria parte do estímulo. Devido à mediocridade do estímulo, a excitabilidade nunca seria completamente consumida e sempre produziria mais excitamento. 
incubados e latentes, de modo que, em momentos de baixa imunidade, podem se proliferar e se manifestar como o que são - discursos fundamentalmente estéticos, morais, religiosos ou políticos.

\section{DISCUSSÃO, CONCLUSÕES E CONSIDERAÇÕES FINAIS}

A partir da análise do discurso foucaultiano e de um exercício arqueogenealógico, nossa pesquisa apontou que a emergência do conceito de obesidade e a patologização dessa condição ocorreram em momentos históricos relativamente recentes no Ocidente, quer dizer, a partir do final do século XVIII; um ponto diferente dos discursos do campo da historiografia da saúde que tentam localizar essa patologização em épocas anteriores.

Além disso, em vez de um objeto constituído cientificamente desde o princípio, como alguns autores sugerem (REPETTO, 1998; HASLAM, 2007; BRAY, 2009), observam-se proposições impregnadas de valores estéticos, ético-morais e religiosos. Desse modo, conclui-se que as alegações médicas daquele período se configuravam como investimentos do saber-poder num deslocamento discursivo do sangue nobre (humoralismo) para o corpo burguês, em que 0 amedrontamento se caracteriza como estratégia privilegiada de propaganda, demandada pela constituição de um novo objeto científico (FEYERABEND, 1989), sendo a quantificação uma ferramenta adequada para o desenvolvimento de uma noção de saúde ancorada na normalidade (CANGUILHEM, 1995).

Após o estabelecimento da medida de massa corporal, desenvolveram-se, ao longo do século XIX, os fundamentos biopolíticos (PELBART, 2003; FOUCAULT, 2008, 2008b) da estatística populacional, ${ }^{22}$ que, principalmente após a $2^{\underline{a}}$ Guerra Mundial, passa a pautar-se por uma política da governamentalidade (FOUCALT, 2006) e extrair a sua legitimidade a partir de conceitos como o de risco e de expectativa de vida.

Ressalta-se que, apesar desta pesquisa ter apresentado discursos sobretudo médicos, a patologização da obesidade não se restringiu ao campo médico, trata-se de uma emergência política e sociocultural que deu-se em várias frentes, sendo encontrados, inclusive, discursos de resistência a esse acontecimento. Como não coube a apresentação desta parte da pesquisa, tivemos que optar por um recorte da pesquisa e esperamos apresentar os demais resultados num outro artigo.

Dada a polissemia e a redundância discursiva que atualmente ressaltam os males da obesidade, às vezes pode ser difícil para algumas pessoas aceitar que junto com os discursos patológicos jazem valores morais e políticos (RIGO, SANTOLIN, 2012; PALMA et al. 2012; SEIXAS; BIRMAN 2012; GOMES, 2006). Assim, para nos situarmos na biopolítica e nos jogos do biopoder (PELPART, 2003; FOUCAULT, 1996, 2006, 2008b) em que se situa a patologização da obesidade, faz-se necessário restituir a sua proveniência. Não para buscar as suas origens, nem para negar os seus malefícios, mas, principalmente, para evidenciar as relações genealógicas que possibilitaram que ela fosse classificada como uma patologia.

22 A principal ferramenta neste sentido permanece sendo a curva normal a partir do cálculo do IMC (desenvolvido por Lambert Adolphe Jacques Quetelet [1796-1874] na segunda metade do século XIX), a qual está relacionada ao conceito de risco e expectativa de vida ao longo do século XX. 


\section{REFERÊNCIAS}

ALLEN, J. Abregé de toute la medecine pratique. Paris: Huart, 1728, v. 2, cap. 8, p.57-58.

AQUINO, Tomas de. Suma teológica. São Paulo: Loyola, 1984.

BANTING, William. Letter on corpulence, addressed to the public. 3. ed. Londres: Harrison, 1864.

BOERHAAVE, Herman. Dr. Boerhaave's academical lectures. Londres: W.Innys, 1746. v. 6.

BRAY, George A. History of obesity. In: WILLIAMS, G.; FRÜHBECK, G. Obesity: science to practice.

Chichester: Wiley-Blackwell, 2009.

BRILLAT-SAVARIN, Jean Anthelme. The physiology of taste; or, transcendental gastronomy. Philadelphia: Lindsay \& Blakiston, 1854.

BRILLAT-SAVARIN, Jean Anthelme. The handbook of dining; or, corpulency and leaness scientifically considered. New York: D. Appleton, 1865.

BROWN, John. The elements of medicine; or, a translation of the elementa medicinæ Brunonis. London: J.Johnson, 1788.

CANGUILHEM, Georges. 0 normal e o patológico. Rio de Janeiro: Forense, 1995.

CHAMBERS, Ephraim. Cyclopaedia. Disponível em: <http://digicoll.library.wisc.edu/cgi-bin/ HistSciTech/HistSciTech-idx?type=turn\&id=HistSciTech.Cyclopaedia02\&entity=HistSciTech. Cyclopaedia02.p0299\&q1=obesity> Acesso em: 15 jan. 2012.

CHAMBERS, Ephraim. Cyclopaedia. Disponível em: <http://digicoll.library.wisc.edu/cgi-bin/ HistSciTech/HistSciTech-idx?type=turn\&id=HistSciTech.Cyclopaedia01\&entity=HistSciTech. Cyclopaedia01.p0760\&q1=fatness> Acesso em: 15 jan. 2012a.

CHAMBERS, Thomas King. Corpulence; or excess of fat in the human body: its relations to chemistry and physiology, its bearings on other diseases, and the value of human life, and its indication of treatment. With an appendix on emaciation. In: THE EDINBURH medical and surgical journal: exhibiting a concise view of the latest and most important discoveries in medicine, surgery and pharmacy. Edinburgh: Adam and Charles Black, 1851. v. 76, Pt.2, Art. II, p.450-469.

CHOMEL, M. N. Dictionnaire œconomique. Paris: Henry Thomas, 1743. p.214.

CORNARO, Luigi. How to live 100 years; or Discourses on the sober life. Disponível em <http://www. soilandhealth.org/02/0201hyglibcat/020105cornaro.html> Acesso em 23 fev. 2011.

CULLEN, William. Lectures on the materia medica. Dublin: Robert Bell, 1775.

DIDEROT, M. (org.). Encyclopédie; ou dictionnaire raisonné des sciences, des arts et des métiers, par une société de gens de lettres. Genene: Pellet, 1777. v. 9. p.537.

ETTMULLER, Michael. Pratique generale de tout le corps humain. Lyon: Thomas Amaulry, 1699, v.1, Cap.18, p.607-616.

ETYMONLINE Dictionary. Lancaster: Douglas Harper, 2001-2014. Disponível em:<http://www. etymonline.com>. Acesso em: 19 ago. 2014.

FERREIRA, Aurélio Buarque de Hollanda. Novo dicionário da língua portuguesa. 2. Ed... Rio de Janeiro: Nova Fronteira, 1984.

FEYERABEND, Paul. Contra o método. 3. ed. Rio de Janeiro: Francisco Alves, 1989.

FLEMYNG, Malcom. A discourse on the nature, causes, and cure of corpulency. London: L. Davis e C. Reymers, 1760.

FOUCAULT, Michel. Segurança, território, população: curso dado no Collège de France (19771978). São Paulo, Martins Fontes, 2008.

FOUCAULT, Michel. Arqueologia do saber.7.ed. Rio de Janeiro: Forense Universitária, 2008a.

FOUCAULT, Michel. Nascimento da biopolítica: curso dado no Collège de France (1978-1979). São Paulo: Martins Fontes, 2008b. 
FOUCAULT, Michel. A governamentalidade. In: BARROS DA MOTTA, M (Org.). Michel Foucault Estratégia, poder- saber (Ditos e escritos: IV). Rio de Janeiro: Forense Universitária, 2006. p. 281305.

FOUCAULT, Michel. Vigiar e punir. 26.ed. Rio de Janeiro: Vozes, 2002.

FOUCAULT, Michel. Os anormais: curso no Collège de France (1974-1975). São Paulo: Martins Fontes, 2001.

FOUCAULT, Michel. 0 nascimento da clínica. 5.ed. Rio de Janeiro: Forense Universitária, 1998. FOUCAULT, Michel. História da sexualidade 2: 0 uso dos prazeres. 8.ed. Rio de Janeiro: Graal, 1998a.

FOUCAULT, Michel. Microfísica do poder. 12.ed. Rio de Janeiro: Graal, 1996.

GOMES, I. M. Obesidade como metáfora contemporânea: uma cruzada saudável em nome do consumo e do risco: Movimento, Porto Alegre, v. 12, n. 3, p. 45-71, set. 2006.

GRAHAM, T. J. Of the reduction of corpulence. In: Sure method improving health, and prolong life; or, a treatise on the art of living long and comfortably, by regulating the diet and regimen. 2. ed. London: Carey, Lea \& Carey, 1827. Seção 1, Cap.3, p.327-337.

HASLAM, David. Obesity: a medical history. Obesity reviews, Oxford, v.8. supl. 1, p.31-36, 2007. JUNGES, J. R. Direito à Saúde, biopoder e bioética. Interface Comunic., Saúde, Educ., v. 13, n.29, p.285-95, abr.jun. 2009. p. 285-295.

KULICK, D.; MENELEY, A. (org.) Fat: the anthropology of an obsession. New York: Penguin Group, 2005.

MAGNER, Lois N. History of medicine. 2. ed. New York: Taylor \& Francis, 2005.

OLIVER, J. Eric. Fat politics. New York: Oxford University, 2006.

PELBART, Peter Pál. Vida Capital: ensaios de biopolítica. São Paulo: lluminuras, 2003.

PALMA, A. et al. Os "pesos" de ser obeso: traços fascistas no ideário de saúde contemporâneo. Movimento, Porto Alegre, v. 18, n. 04, p. 99-119, out/dez de 2012.

REPETTO, Giuseppe. Histórico da obesidade. In: HALPERN, A. et al. Obesidade. São Paulo: Lemos, 1998. Cap. 1. P. 4-22.

RIGO, L. C.; SANTOLIN, C. B. Combate à obesidade: uma análise da legislação brasileira.

Movimento, Porto Alegre, v. 18, n. 2, p. 279-296, abr/jun de 2012.

SAUVAGES, François Boussier. Polysarcia; la corpulence. In: __. Nosologie méthodique; ou distribution des maladies en classes, en genres et en especes, suivant I'Esprit de Sydenham, \& la méthode des Botanistes. Lyon: Jean-Marie Bruyset, 1772. v.9, p.106-109.

SEIXAS, Cristiane Marques; BIRMAN, Joel. O peso do patológico: biopolítica e vida nua. História, Ciência e Saúde-Manguinhos, Rio de Janeiro, v.19, n.1, jan.-mar. 2012. p.13-26.

STRUNA, Nancy. Pesquisa histórica em atividade física. In: THOMAS, J. R.; NELSON, J. K.; SILVERMAN, S. J. Métodos de pesquisa em atividade física. 5. ed. Porto Alegre: Artmed, 2007, Cap. 12 , p. 189-201.

THE SPECTATOR for the week ending saturday. London, n. 1924, 13 maio, p.520-521,1865. THOMAS, Jerry R.; NELSON, Jack K.; SILVERMAN, Stephen J. Métodos de pesquisa em atividade física. 5. ed. Porto Alegre: Artmed, 2007. 